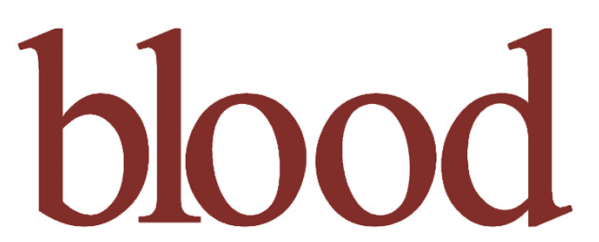

2002 100: 734-735

doi:10.1182/blood-2002-03-0821

\title{
Leu208Val and Ile181Leu variants of cytochrome P450CYP2C9 are not related to the acenocoumarol dose requirement in a Spanish population
}

José Zarza, José Hermida, Ramón Montes, Ignacio Alberca, Mari?a Luz López and Eduardo Rocha

Updated information and services can be found at:

http://bloodjournal.hematologylibrary.org/content/100/2/734.full.html

Information about reproducing this article in parts or in its entirety may be found online at:

http://bloodjournal.hematologylibrary.org/site/misc/rights.xhtml\#repub_requests

Information about ordering reprints may be found online at:

http://bloodjournal.hematologylibrary.org/site/misc/rights.xhtml\#reprints

Information about subscriptions and ASH membership may be found online at:

http://bloodjournal.hematologylibrary.org/site/subscriptions/index.xhtml

Blood (print ISSN 0006-4971, online ISSN 1528-0020), is published weekly

by the American Society of Hematology, 2021 L St, NW, Suite 900,

Washington DC 20036.

Copyright 2011 by The American Society of Hematology; all rights reserved.

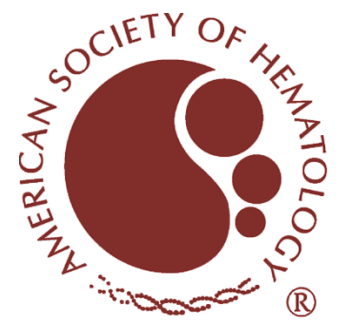


9. Wallace DF, Pedersen P, Dixon JL, et al. Novel mutation in ferroportin1 is associated with autosomal dominant hemochromatosis. Blood. 2002;100: 692-694.
10. Fleming RE, Sly WS. Ferroportin mutation in autosomal dominant hemochromatosis: loss of function, gain in understanding. $\mathrm{J}$ Clin Invest. 2001;108:521-522.

\section{To the editor:}

\section{Leu208Val and lle181Leu variants of cytochrome P450 CYP2C9 are not related to the acenocoumarol dose requirement in a Spanish population}

Cytochrome P450 CYP2C9 is the principal catalyst of warfarin and acenocoumarol hydroxilation reactions in human liver microsomes. ${ }^{1}$ There is a growing interest in the identification of genetic variants of cytochrome $\mathrm{P} 450$ CYP2C9, which can modify its ability to inactivate warfarin and acenocoumarol, since a reduced CYP2C9 activity on these drugs would put patients at risk of over anticoagulation and subsequent bleeding complications. $^{2}$ 2C9*2 (Arg144Cys) and 2C9*3 (Ile359Leu) variant alleles of this cytochrome have been associated with increased sensitivity to warfarin and acenocoumarol. ${ }^{3-6}$ But the allelic frequencies for these variants differ considerably among different ethnic groups: Caucasians carry the $2 C 9 * 2$ and $2 C 9 * 3$ variants ( $8 \%$ to $20 \%$ and $6 \%$ to $10 \%$, respectively) more frequently than Asians do ( $0 \%$ and $2 \%$ to $5 \%$, respectively). ${ }^{7}$ Recently, Leung et al ${ }^{8}$ have identified several genetic polymorphisms of cytochrome P450 CYP2C9 in a Chinese population. Two of them, Leu208Val and Ile181Leu, could have importance in the sensitivity to oral anticoagulant treatment in Chinese patients. Allele 208 Val is more frequent than the Caucasian wild-type Leu208 in the Chinese population (75\% heterozygotes and $19 \%$ homozygotes) and is associated with a lower warfarin dose requirement, which could explain why the Chinese population is more sensitive to warfarin than the Caucasian one. The Ile181Leu allelic variant was present in $9 \%$ of studied patients in heterozygous form and was associated with a higher warfarin dose requirement in that population. ${ }^{8}$

We have studied Leu208Val and Ile181Leu variants in 106 Spanish anticoagulated patients with a stable requirement for acenocoumarol to keep the international normalized ratio (INR) between 2 and 3.2 (41 patients required no more than $7 \mathrm{mg} / \mathrm{wk}$ acenocoumarol; 44 patients required between $7 \mathrm{mg} / \mathrm{wk}$ and 28 $\mathrm{mg} / \mathrm{wk}$; finally, 21 patients required more than $28 \mathrm{mg} / \mathrm{wk}$ ). The population is described in detail elsewhere. ${ }^{6}$ Genotyping for Leu208Val and Ile181Leu was done by polymerase chain reaction followed by digestion with restriction enzyme. Primers for genetic analysis were TGTGCTCCCTGCAATGTGATCTGGTC (forward) and TGGCCTTACCTGGATCCAGGGGCTGGTC (reverse). A forced mismatch was included in position 3 from the $3^{\prime}$ end of forward primer to create in combination with 527ATT $>$ CTT (polymorphism Ile181Leu) a restriction site for NlaIV. The reverse primer also has a forced mismatch in position 3 from the $3^{\prime}$ end to create in combination with $608 \mathrm{TTG}>\mathrm{GTG}$ (polymorphism Leu208Val) a restriction site for Tsp45I.
Neither Leu208Val nor the Ile181Leu variants were detected in any of the studied patients, indicating that neither of these genetic variants is involved in the variability of acenocoumarol requirement in this Spanish population: if these polymorphisms played a significant role in determining the acenocoumarol dosage in this population, we should have found some patients carrying the Leu208Val variant in the group with low acenocoumarol requirement and patients carrying the Ile181Leu variant in the high-dose group.

In conclusion, we demonstrate that the Leu208Val and the Ile181Leu polymorphisms of cytochrome P450 CYP2C9 do not seem to play an important role in sensitivity to acenocoumarol in the Spanish population. Factors such as $2 C 9 * 2$ and $2 C 9 * 3$ variants of $C Y P 2 C 9$, age, sex, pharmacologic interactions, or associated diseases do not completely account for the interindividual differences in sensitivity to anticoagulant treatment. Therefore, it is probable that unknown genetic variants influencing the coumarin metabolism, which are perhaps different in different populations, will be described in the near future.

\section{José Zarza, José Hermida, Ramón Montes, Ignacio Alberca, María Luz López, and Eduardo Rocha}

Correspondence: Eduardo Rocha, University of Navarra, Haematology, Avda Pío XII 36, Pamplona 31008, Spain; e-mail: erocha@unav.es

\section{References}

1. Hermans JJ, Thijssen HH. Human liver microsomal metabolism of the enantiomers of warfarin and acenocoumarol: P450 isozyme diversity determines the differences in their pharmacokinetics. Br J Pharmacol. 1993;110:482-490.

2. Fihn SD, McDonell M, Martin D, et al. Risk factors for complications of chronic anticoagulation: a multicenter study. Warfarin Optimized Outpatient Follow-up Study Group. Ann Intern Med. 1993;118:511-520.

3. Aithal GP, Day CP, Kesteven PJ, Daly AK. Association of polymorphisms in the cytochrome P450 CYP2C9 with warfarin dose requirement and risk of bleeding complications. Lancet. 1999;353:717-719.

4. Taube J, Halsall D, Baglin T. Influence of cytochrome P-450 CYP2C9 polymorphisms on warfarin sensitivity and risk of over-anticoagulation in patients on long-term treatment. Blood. 2000;96:1816-1819.

5. Margaglione M, Colaizzo D, D'Andrea G, et al. Genetic modulation of oral anticoagulation with warfarin. Thromb Haemost. 2000;84:775-778.

6. Hermida J, Zarza J, Alberca I, et al. Differential effects of $2 \mathrm{C9} 33$ and $2 \mathrm{C9} 92$ variants of cytochrome P-450 CYP2C9 on acenocoumarol sensitivity. Blood. 2002;99:4237-4239.

7. Takahashi $\mathrm{H}$, Echizen $\mathrm{H}$. Pharmacogenetics of warfarin elimination and its clinical implications. Clin Pharmacokinet. 2001;40:587-603.

8. Leung AY, Chow HC, Kwong YL, et al. Genetic polymorphism in exon 4 of cytochrome P450 CYP2C9 may be associated with warfarin sensitivity in Chinese patients. Blood. 2001;98:2584-2587. 